\title{
A glance back in time: Two decades at the John W. Scott Health Sciences Library
}

\author{
Sandra Shores
}

This summer, the Health Sciences Library at the University of Alberta in Edmonton celebrates 20 years at its current location in the Walter C. Mackenzie Health Sciences Centre. Named for the Dean of Medicine from 1948 to 1959, the John W. Scott Health Sciences Library opened its doors to the public in early August 1984. Plans for the new library and health sciences centre went through numerous iterations from the mid 1960s until construction began in the late 1970s. Regardless of the library's location, from the new facility back through its previous sites, staff members have always worked in partnership with the rest of the university library system and the broader healthcare community to provide innovative services to students, faculty, researchers, and clinicians in central and northern Alberta.

Within the Canadian context, the University of Alberta ranks as an older institution since it opened in 1908. The first medical school class began studies in 1913, and the Department of Pharmacy, a "sub-faculty" of Dentistry, and the Alberta Research Council were all established within the next few years. The School of Nursing opened in 1924, and the School of Physiotherapy in 1954. The health sciences faculties now include Medicine and Dentistry, Nursing, Pharmacy, and Rehabilitation Medicine, each with a full range of undergraduate and graduate programs.

The reading materials to support these programs were originally housed in the university's only library in Athabasca Hall, one of the earliest multipurpose buildings on campus and still an architectural treasure. The collection moved into the new Arts Building a few years later, then into Rutherford Library when it opened in 1951. In 1963, the collection found a home in Cameron Library, which has primarily served the sciences since its opening.

Although the Medical Library within Cameron served students, faculty, and clinicians well, as new teaching and research buildings were erected at the south end of campus around the University Hospital, users felt inconvenienced by the Cameron Library's location. The number of books and photocopied articles delivered to the hospital reading room rose steadily. At the same time, medical faculty and University Hospital staff began to dream of a new specialist hospital that would provide greater opportunities for research and much needed new facilities for patient care.

S. Shores. John W. Scott Health Sciences Library, University of Alberta, Edmonton, AB T6G 2R7, Canada (e-mail: sandra.shores@ualberta.ca).
Enthusiasm for this specialist hospital, which on paper was named the Centennial Hospital, marked the first planning stage for a state-of-the-art health sciences centre, which would include an equally progressive health sciences library. In 1971, the Social Credit government in Alberta was defeated by Peter Lougheed's Conservatives, who rejected the Centennial Hospital plans. Within a few years though, the young government commissioned and then endorsed a new plan for a university health sciences centre in Edmonton.

While the faculty and staff at the University Hospital lacked enthusiasm for the vision expressed in the government-backed Clarkson Report, they worked within its constraints and won some modifications. Government approval to fund the health sciences centre loosely coincided with the establishment of the Alberta Heritage Foundation for Medical Research, marking a new era in health care and research in the province of Alberta. Phase 1 of the centre was to open in 1984 and include the new health sciences library.

Bruce Peel, then Chief University Librarian, and Phyllis Russell, the Medical Librarian, planned extensively for the new library, basing decisions on careful research into user needs, publishing trends, and expected growth in teaching and research. They were originally allotted 20000 square feet of space and successfully lobbied to increase that to more than 44000 square feet. Around the time the library opened, it served an identifiable user population of about 4500 students, faculty, researchers, and clinicians in the city and beyond. Research funding for the health sciences faculties then amounted to a little more than CAN\$3 million annually. As the library's 20th anniversary approaches, the health sciences student body alone surpasses 4500, and external research funding in these faculties exceeds CAN\$100 million.

Eberhard Zeidler, well known for such landmarks as Canada Place in Vancouver and the Eaton Centre in Toronto, was chosen lead architect for the project. Zeidler integrated striking features typical of his style into both the Scott Library and the Mackenzie Health Sciences Centre as a whole. Lengthy skylights, massive glass ceilings, and extensive use of internal windows allow natural light to flow throughout the complex. Separate wings are joined on each floor by bridges marked by bright white railings, large round lanterns, and rows of potted plants. Atriums and courtyards fill the spaces between separate sections of the centre. The bright, airy, and open design suits Edmonton's cold northern climate and vastly improves upon the early 20th-century hospital design it replaced. 
The Scott Library occupies three storeys of long, rectangular space in the northeast corner of the complex. A wide skylight runs two-thirds the length of the library, below which the top two floors are left open down to the lowest level. As elsewhere, thick white railings ring these openings, and the tendrils and blossoms of the surrounding original live plants stretched towards the lower two floors, even matching the colour of the upholstery. Cost reductions resulted in silk replacements some years ago, but despite this and numerous other physical changes, the fresh, bright look and feel of the library remain.

When the Scott Library opened, it provided a wide a range of services and resources appropriate to its clientele. The top floor, on which people enter the library, included most of the staffed services such as circulation, reference, and a large media library. One of the celebrated new services, the media library housed collections of audio and video tapes, slide sets, films, film strips, every variety of equipment needed to access these items, group viewing rooms, and two dozen individual viewing carrels. The circulation area contained lockers accessible from outside the library so that staff could leave materials for busy clinicians to retrieve after regular hours. The circulation office was also a destination of the hospital's telelift system, allowing for the quick and direct transport of physical items such as specimens, radiographs, and, in the case of the library, books and journals.

The reference area had space for complete runs of all the major print indexes and catalogues in the health sciences plus Chemical Abstracts, Biological Abstracts, and the ISI indexes. The plans also included ample room for an expanding card catalogue. Unfortunately, the designers inserted a nursing station as the reference desk, which never lent itself well to reference interviews and consultations. At the time of opening, five reference librarians were to share one large office that was equipped with two typing tables and five telephone stands. The head librarian and reference head had individual offices. Plans for the library were sufficient for the time in providing one small room for the MEDLINE terminal and an online catalogue station. In 1984, this meant a single dot matrix DECwriter terminal with a 300 baud modem.

The middle floor of the library included the book collection, four group study rooms, a generous number of offices to be used as faculty carrels, a typing room equipped with eight typewriters, self-serve photocopiers, and, typical of that time, a smoking room. A large compact storage room with moveable shelving was built into the middle floor, allowing for local storage of low use items.

The lower floor housed the print and unbound journal collection, and a temperature and humidity controlled rare book room. There was also a staffed photocopy service that fully occupied one employee for the years it remained open. Finally, a classroom accommodating approximately 40 people completed the lower floor and allowed librarians to deliver lecture-styled instruction within the library. There were satellite microfiche catalogues on the two lower floors and intercoms to reach the reference and circulation desks. In all, there was seating for more than 550 people throughout the three floors. Regrettably, Phyllis Russell resigned from her position for health reasons before the move to the new li- brary, but she left a remarkable legacy in her plans and vision. The rare book room is named in her honour.

As could be expected, the library has faced many pressures over the last 20 years, resulting in significant changes to services and the physical use of space. The most noticeable changes have come about because of the computerization of library services and the more recent digitization of collections. By 1984, automation had begun its incursion into the university library system. Although plans included a MEDLINE terminal, an online catalogue, and a computer program to measure the spacing of the bound journal collection, no one anticipated end user searching and its impact on reference collections and services. While staff at the time might have had a sense of the role computers would play in searching, they cannot be faulted for failing to foresee the impact that the Web would have on library collections.

Within a few years of opening, the one MEDLINE DECwriter terminal became insufficient for the volume of mediated searching that was being done in the library. At the request of faculty members and clinicians, the reference librarians were averaging more than 100 MEDLINE searches a month in addition to some Dialog and BRS searches. Soon, PCs were added to the DECwriter and moved into the reference librarians' office, and the librarians started to use some of the faculty carrels. Their new private offices led to increased productivity and allowed for consultations with clients, an emerging role for librarians.

Once end user searching became a reality, CD-ROM stations were installed in the reference area along with terminals for accessing the catalogue. These, of course, were eventually replaced by a suite of networked public workstations with Internet access. Given the range of databases currently available, all of the print indexes except for old volumes of Index Medicus have recently been moved to off-site storage. The many bays of shelving that held them are also gone leaving well used space for group study. A wireless network was installed in 2003, something that would have been unfathomable 20 years ago.

The early years of the Web coincided with a decrease in the importance of the media library. Before the Internet and the World Wide Web, many types of devices were required to listen to and view all sorts of audiovisual formats. Now, most types of files are accessible through the medium of a Web browser. The media library closed in the late 1990s when the media librarian retired. Many of the resources were discarded because of their obsolescence, although a portion of the video collection was integrated into the general Scott collection after securing public performance rights. Copyright, public performance rights, and licensing obligations, an ever present concern in today's libraries, were given much less attention in 1984 .

The reference desk and collection were moved to the space formerly occupied by the media library, allowing for the design of a more functional reference desk and reading area. As the use of electronic resources increased, the need for items such as the 24-hour lockers, the typing room, and the staffed photocopy service decreased and were eventually shut down or removed from the library. The style of library instruction also changed, with hands-on computer-based courses becoming the norm. The classroom was taken over by one of the residency programs that had no space in the 
hospital for study and meeting, and the librarians now teach in smaller, wired seminar rooms, smart classrooms in the faculties, or computer labs elsewhere on campus. When the library opened in 1984, 60 instruction sessions were attended by more than 1000 people. In 2003, well over 200 sessions were attended by nearly 6000 participants.

Budgetary restraint and staff changes also contributed to change. When the library opened, there were 6 librarians and 18 support staff plus considerable casual staffing. The library now has 8 librarians, approximately 14 support staff and very few hourly, casual staff. With this smaller staff complement, the library nonetheless serves a more diverse community, has a larger, more complex collection, and supports a much more intensive teaching and research agenda than in 1984. Over the last 20 years, the Scott Library has become more fully integrated within the university library system, and the system as a whole has outsourced some services and reduced the size of management. Thus the Scott Library has been able to concentrate on its core collections and services.

A medical or health sciences librarian no longer heads the Scott Library. Instead, one associate director oversees all of the science libraries on campus. Almost all technical services work is done centrally for the whole university, and most cataloguing is outsourced. The interlibrary loans functions have recently been fully integrated with the central service, with Ariel stations now installed in the former staffed photocopy room. A few years ago, the moveable shelving was taken out of the in-house compact storage room. Low use items, including print copies of current journal issues received electronically, are now housed in the university libraries' off-site facility with daily delivery service back to campus. The former compact storage room now houses older, low demand microform collections for all campus libraries.

Amidst these changes, there has been one constant. Gate counts have continued to rise steadily and have increased sharply in the last year. Regardless of the format of materials collected, the ease of access from outside the library, or the move to provide reference and teaching services virtually, people still come to the library. They come to think, to read, and to work and learn with others. As in many other libraries, drinking is now permitted making time in the library a more relaxed and enjoyable experience. Over the short term, the Scott Library aims to provide more group study space and soft seating, increase the scope of wireless access, and install more computer workstations with a broader range of software.

While the Scott Library has gone through many changes over the last 20 years, the larger community in which it operates has also experienced considerable change. When the library opened in 1984, the health care system in Alberta had not undergone regionalization. Hospitals and other health care institutions operated somewhat independently from each other, and with no Internet and other established networks, many urban and small rural hospitals ran their own libraries. The Scott Library Annual Reports from the 1980s note many instances of consultation with rural hospitals on how to organize and operate their libraries. Scott staff also provided a literature search and document delivery service for physicians in the northern half of the province, with the University of Calgary serving the south.

Today, many small hospital libraries in the province have closed, in addition to a number of other specialized libraries such as those attached to nursing schools and organizations like the former Alberta Hospital Association. The service to physicians has ceased, but instead, the two university health sciences libraries operate the Health Knowledge Network (HKN). HKN provides databases and other electronic resources primarily to health regions and post-secondary institutions in Alberta and beyond. In addition to partnering with the University of Calgary to collaborate on HKN, the University of Alberta recently partnered with Capital Health to open the Regional Drug Information Centre within the Scott Library. This unique centre is staffed by two pharmacists, one of whom is also a librarian. They support the drug information needs of health professionals in the entire region, participate in the education of pharmacy students, and work with the librarians on difficult drug-related reference questions.

The Scott librarians have also made a significant contribution to the university and community beyond the library. In 1985, they were instrumental in founding the Northern Alberta Health Libraries Association (NAHLA), a chapter of the Canadian Health Libraries Association / Association des bibliothèques de la santé du Canada (CHLA / ABSC). Various Scott librarians have held every executive position on NAHLA since its foundation. Leslie Sutherland and Linda Slater have each served as secretary of CHLA / ABSC, and Lea Starr served as president 1995-1996. NAHLA has hosted the CHLA / ABSC conference twice, in 1990, and again in 2003. The Scott Library's current associate director, Margaret Law, was president of the Canadian Library Association in 2001. Scott librarians regularly contribute to the education of new professionals teaching courses as publishing, cataloguing, digital reference, and health libraries at the School of Library and Information Studies at the University of Alberta. Jeanette Buckingham has also served as president of the academic staff association on campus.

At the time of writing, three new health sciences buildings are under construction on the pockets of land immediately surrounding the Mackenzie Centre, and two more are in the planning stages. These buildings are for the Alberta Heart Institute, a gastroenterology facility, and more research, teaching, and clinical space. Occasionally, the Scott Library vibrates as large machinery crushes the recently unearthed lower foundations of the original University Hospital to make way for some of this construction. As the health sciences end of campus expands, the University plans to continue increasing enrollment in most undergraduate and graduate programs. The Scott Health Sciences Library will remain a vital resource, service, and place for this burgeoning clientele, and the staff are poised to meet the challenges of the next 20 years and beyond. 